were not comparable, having widely differing renal histology. The use of steroids in this situation must remain an open question.

\section{Summary}

Seven patients with fatal acute glomerulonephritis referred to a haemodialysis unit in a three-year period were between 53 and 78 years of age. The presenting features and natural history of acute glomerulonephritis in this age group of ten differ from those commonly seen in younger patients. The rarity of the disease in the middle-aged and elderly, coupled with the atypical presentation of most of the patients, made the clinical diagnosis difficult.

The histological changes included necrosis of glomerular tufts, obliteration of Bowman's space by proliferation of the capsular epithelium, and endothelial proliferation with glomerular exudate. Renal biopsy is valuable in both establishing the diagnosis and assessing the severity of the disease, and so avoiding submission of patients with no hope of recovery to unnecessary treatment.
We are grateful to Professor J. Anderson for permission to report these cases, and to Professor H. A. Magnus for his advice. The photomicrographs were prepared by Mr. George Harwood.

\section{REFERENCES}

Alwall, N., Erlanson, P., Tornberg, A., Fajers, C. M., and Moëll, H. (1958). Acta med. scand., 161, 85 .

Baker, S. B. de C., and Williams, R. T. (1963). Brit. med. 7., 1, 1655.

Berlyne, G. M., and Baker, S. B. de C. (1964). Quart. F. Med., 33, 105. Bialestock, D., and Tange, J. D. (1959). Aust. Ann. Med., 8, 281 .

Brun, C., Gorsmen, H., Hilden, T., Iversen, P., and Raaschou, F. (1958). Acta med. scand., 160, 155 .

Ellis, Acta med. (1942). Lancet, 1,1 .

Fishberg, A. M. (1954). Hypertension and Nephritis, 5th ed., p. 542. Lea and Febiger, Philadelphia.

Harrison. C. V., Loughridge, L. W., and Milne, M. D. (1964). Quart. 7. Med., 33, 39 .

Jennings, R. B., and Earle, D. P. (1961). 7. clin. Invest., 40, 1525.

Lancet, 1964, 1, 1429.

Lee, H. A., and Holden, C. E. A. (1964). Postgrad. med. 7., 40, 326. Merrill, J. P. (1957). f. chron. Dis., 5, 138

Nakamoto, S., Dunea, G., Kolff, W. J., and McCormack, L. J. (1965). Ann, intern. Med. 63 , Kolff,

Nesson, R. M.. and Robbins, S. L. (1960). Arch. intern. Med., 105, 23. Persoff, D. (1965). Lancet, 1, 347.

Samiy, A. H., Field, R. A., and Merrill, J. P. (1961). Ann. intern. Med. 54,603 .

\title{
Yersinia enterocolitica (Pasteurella X) in Human Enteric Infections
}

\author{
STEN WINBLAD,* M.D. ; BIRGITTA NILEHN,* M.D.; NILS H. STERNBY,† M.D.
}

[With Special Plate]

Brit. med. F., 1966, 2, 1363-1366

The aetiological factors in the acute inflammation of the ileocaecal region-appendicitis, terminal ileitis, and mesenteric lymphadenitis-are poorly understood, but the microflora in these conditions has recently received increasing attention.

In 1954 Knapp and Masshoff found Yersinia pseudotuberculosis (syn. Pasteurella pseudotuberculosis) in inflamed mesenteric lymph nodes. Since then several authors (Knapp and Steuer, 1956 ; Kiaer, 1960 ; Knapp, 1963 ; Mollaret, 1960, 1962 ; Knapp and Thal, 1963) have thoroughly described the bacteriology, serology, and histopathology of Masshoff's disease-that is, mesenteric lymphadenitis caused by $Y$. pseudotuberculosis. In $1957 \mathrm{Kjellén}$ et al. isolated adenovirus from inflamed mesenteric lymph nodes in patients with acute abdominal disease. They also observed rising antibody titres against this virus. Similar observations have been made by Hannoun et al. (1961). Carlsson, Ryd, and Sternby (1964), in this hospital, reported the finding of Yersinia enterocolitica (syn. Pasteurella $X$ ) in a mesenteric lymph node from a patient with acute terminal ileitis and mesenteric lymphadenitis but an apparently normal appendix. Agglutinating antibodies against the patient's own strain developed.

So far as we know $Y$. enterocoiitica has been isolated from man only three times previously-that is, in two cases describcd by Hässig, Karrer, and Pusterla (1949) and in one case described by Mollaret (1965), where the bacterium was isolated by Wyler. The taxonomic position of the Bacterium enterocoliticum strains described by Schleifstein and Coleman (1939) seems, however, still to be questionable.

The occurrence of $Y$. enterocolitica in animals-chinchillas, hares, pigs, and dogs-is well known (Dickinson and Mocquot,

* Institute of Clinical Bacteriology, University of Lund, General Hospital, Malmö, Sweden.

t Institute of Clinical Pathology, University of Lund, General Hospital,
1961 ; Becht, 1962 ; Daniéls and Goudzwaard, 1963 ; Daniéls, 1963 ; Akkermans and Terpstra, 1963 ; Knapp and Thal, 1963 ; Mollaret and Chevalier, 1964 ; Mollaret and Lucas, 1965). The name Yersinia enterocolitica was proposed by Frederiksen (1964).

The finding of $Y$. enterocolitica in this department prompted us to start an investigation of its occurrence in human beings. This report is based on the preliminary results of serological studies on various groups of patients and healthy persons, tested for agglutinins against $Y$. enterocolitica; some groups were also tested for agglutinins against $Y$. pseudotuberculosis type I. Preliminary bacteriological and histopathological data are also included.

\section{Methods and Material}

\section{Antigen Preparation}

The $Y$. enterocolitica antigens for routine agglutination tests were prepared from strain "Winblad," isolated from the case described by Carlsson et al. (1964). Antigens were also preparcd from the following $Y$. enterocolitica strains of chinchilla, canine, and human origin: Siegmann 268 ; Daniéls 975, 905, 924, 931 ; Becht 18, 51, 200 ; Frederiksen P 71 ; Hässig (homo). O antigen from these strains and from strain Winblad gave the same results with positive patient sera and rabbit antisera prepared against strain Winblad in all cases except one (strain Frederiksen $\mathrm{P}$ 71).

$O$ Antigen.-Human blood-agar plates were seeded with the $S$ form of the strain and were incubated for 48 hours at $22^{\circ} \mathrm{C}$. The culture was collected in saline, washed, and autoclaved at $120^{\circ}$ C. for two and a half hours. It was then washed repeatedly and suspended in saline for the use in tube agglutination. 
OH Antigen.-Human blood-agar cultures were prepared, collected, and washed in the way described above. The deposit was suspended in $0.5 \%$ formalin and left at $22^{\circ} \mathrm{C}$. overnight, washed, and suspended in saline for tube agglutination.

In $Y$. enterocolitica serology we found the agglutination reaction with $\mathrm{O}$ antigen to be preferable to the agglutination with $\mathrm{OH}$ antigen and to complement-fixation methods. In accordance with Knapp and Steuer (1956), the $\mathrm{OH}$ antigen was chosen for routine test for $Y$. pseudotuberculosis type I agglutinins. This was prepared in the same way as $Y$. enterocolitica $\mathrm{OH}$ antigen.

\section{Rabbit Immune Sera}

Rabbits received weekly intravenous injections-in the first week $0.5 \mathrm{ml}$., and thereafter $1 \mathrm{ml}$. of $Y$. enterocolitica antigen suspension. The animals were bled in the fifth week. Oantigen and $\mathrm{OH}$-antigen preparations were given in separate immunization series. The rabbits used did not show any detectable agglutinins before immunization. After immunization titres between $1 / 640$ and $1 / 2,560$ were found.

\section{Agglutination Method}

The sera were inactivated at $56^{\circ} \mathrm{C}$. for 30 minutes, and a twofold dilution series in saline was set up, starting with dilution 1 in 10 . Each tube contained $0.5 \mathrm{ml}$. of serum dilution and $0.25 \mathrm{ml}$. of antigen suspension. After incubation overnight at $52^{\circ} \mathrm{C}$. in a water-bath the results were read with the aid of a loupe. The agglutinate was finely granular. The end-point of the reaction was easily recognized.

\section{Culture of $Y$. enterocolitica}

Culture has been done in only a small group of the patients presented here, and almost exclusively from surgical specimens such as lymph nodes and appendices and in some cases from faeces. The culture technique described by Winblad, Niléhn, and Jonsson (1966) was used. The identification of the strains isolated will be described in further detail by one of us (B. N.).

\section{Serum Material}

Sera were obtained from the following sources:

1. 95 patients subjected to appendicectomy because of symptoms suggesting acute appendicitis.

(a) Diagnosis: acute terminal ileitis (often with associated mesenteric lymphadenitis), 25 patients.

(b) Diagnosis: mesenteric lymphadenitis, 8 patients.

(c) Diagnosis: acute appendicitis, 45 patients.

(d) No pathological lesions observed, 17 patients.

2. 22 patients with the diagnosis of chronic regional ileitis (Crohn's disease) (Crohn and Yarnis, 1958).

3. 148 patients with diarrhoea of varying origin (14 with salmonella infections and 14 with the diagnosis ulcerative colitis).

4. 1,351 in-patients of the departments of internal medicine and infectious diseases, sera sent for routine serological tests for syphilis.

5. 431 blood donors.

Groups 4 and 5 served as controls.

From the patients in groups $1 \mathrm{a}, 1 \mathrm{~b}, 1 \mathrm{c}$, and $1 \mathrm{~d}$ repeated serum samples were usually received, the first in the acute phase of the disease-that is, at the time of operation-and the second at least six days after the onset of symptoms. In cases where only one sample was received it was taken more than six days after the onset of the symptoms. A few patients were followed up serologically for several months. In groups 2, 3, 4, and 5, as a rule, only one serum sample was received.

\section{Results}

Patients Subjected to Appendicectomy because of Symptoms Suggesting Acute Appendicitis

The serological results are given in Table I. In 25 patients operation revealed an affection of the distal part of the ileurn, associated with enlarged mesenteric lymph nodes in 21 cases. As a rule serum samples taken during the first days of illness did not show any detectable $Y$. enterocolitica agglutinins. A second sample, however, taken more than six days after the onset of the symptoms, in 18 cases showed $Y$. enterocolitica $\mathrm{O}$ agglutinin titres $\geqslant 1 / 40$. In several cases rather high titres were seen-that is, $\geqslant 1 / 1,280$. In one patient with acute terminal ileitis and with negative $Y$. enterocolitica agglutination repeated tests showed high agglutinin titres against $Y$. pseudotuberculosis $\mathrm{OH}$ antigen, type 1 . Fig. 1 illustrates the antibody curve in this case during an observation time of about eight months.

TABLE I.-Incidence of $Y$. enterocolitica Agglutinins and $Y$. pseudotuberculosis Type I Agglutinins in Patients Appendectomized Because of Symptoms Suggesting Acute Appendicitis

\begin{tabular}{|c|c|c|c|c|c|c|c|}
\hline \multirow{2}{*}{$\begin{array}{l}\text { Diagnosis } \\
\text { after } \\
\text { Operation }\end{array}$} & \multirow[t]{2}{*}{ Total } & \multicolumn{5}{|c|}{$\begin{array}{c}\text { Distribution of } \\
\text { Y. enterocolitica Agglutinins } \\
\text { (Maximal Titre) }\end{array}$} & \multirow{2}{*}{$\begin{array}{l}\text { Y. pseudo- } \\
\text { tuberculosi } \\
\text { Type I- } \\
\text { Agglut: } \\
\geqslant 1 / 40\end{array}$} \\
\hline & & $\leqslant 1 / 10$ & $1 / 20$ & $1 / 40$ & $1 / 80$ & $\geqslant 1 / 160$ & \\
\hline \multirow{3}{*}{$\begin{array}{l}\text { Acute terminal ileitis } \\
\text { Mesenteric lymph- } \\
\text { adenitis . . } \\
\text { Acute appendicitis } \\
\text { No pathological } \\
\text { lesions ... .. }\end{array}$} & 25 & 6 & 1 & 3 & $4^{*}$ & $11^{*}$ & 1 \\
\hline & $\begin{array}{r}8 \\
45\end{array}$ & $\begin{array}{r}2 \\
35\end{array}$ & $\begin{array}{l}1 \\
2\end{array}$ & - & $\begin{array}{l}2 \\
4\end{array}$ & $\frac{3 t}{3}$ & 1 \\
\hline & 17 & 14 & - & - & - & $3 f$ & 1 \\
\hline
\end{tabular}

* Positive culture of $Y$. enterocolitica from 5 patients.

+ Positive culture of $Y$. enterocolitica from 1 patient.

$\ddagger$ Positive culture of $Y$. enterocolitica from 2 patients.

In eight patients operation revealed only enlarged mesenteric lymph nodes. $Y$. cnterocolitica $\mathrm{O}$ agglutinins were found in five of those cases in titres $\geqslant 1 / 80$ when serum samples were taken more than six days after the onset of symptoms. $Y$. pseudotuberculosis type 1 agglutinins were found in one patient who was serologically negative to $Y$. enterocolitica.

In 45 patients the post-operative diagnosis was acute appendicitis. In seven the $Y$. enterocolitica agglutinins reached titres

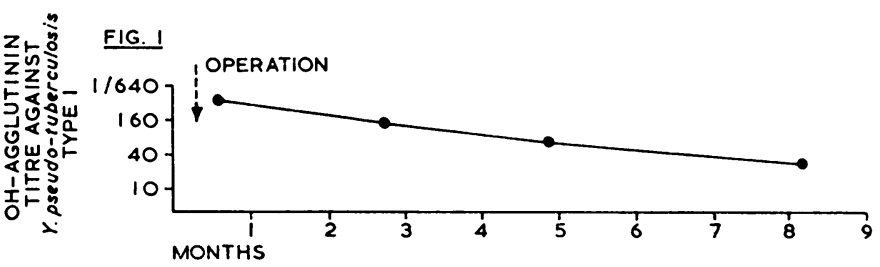

FIG. 1.-OH agglurinins against $Y$. pseudotuberculosis type I in serum from a patient with acute terminal ileitis and mesenteric lymphadenitis.

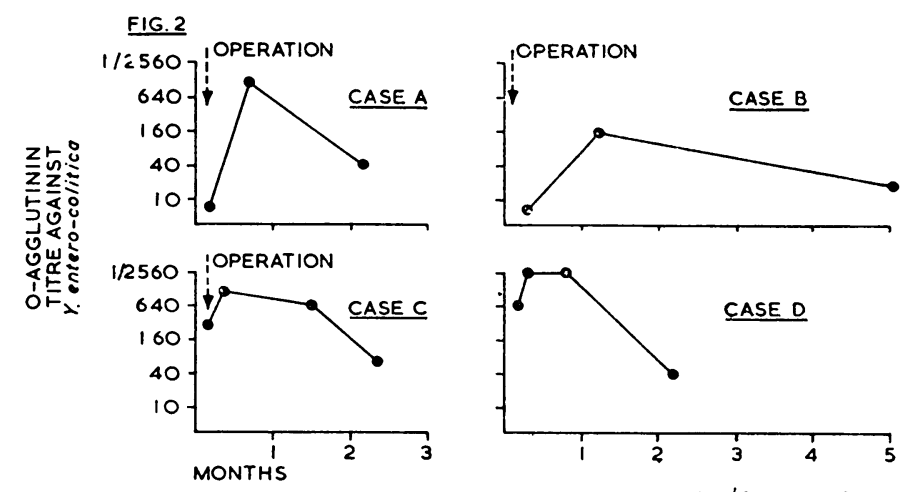

FIG. 2.-Y. enterocolitica $O$ agglutinin titre curves in four patients appendectomized because of svmptoms suggesting acute appendicitis. Case A: Acute terminal ileitis and mesenteric lymphadenitis. Positive $Y$. enterocolitica culture. Case B: Acute terminal ileitis and mesenteric lymphadenitis. Positive Y. enterocolitica culture. Case C: Mesenteric Lymphadenitis. Case D: Appendectomized. No pathological lesions. Positive $Y$. enterocolitica culture. 
$\geqslant 1 / 80$. Agglutinins against $Y$. pseudotuberculosis were not seen in any case.

In 17 patients where the symptoms led to appendicectomy no pathological lesions of the appendix, the intestines, or the mesenteric lymph nodes were seen at operation. Three patients showed $Y$. enterocolitica agglutinin titres $\geqslant 1 / 160$ and one patient $Y$. pseudotuberculosis type 1 agglutinins in a titre of $1 / 40$.

Fig. 2 illustrates two cases of acute terminal ileitis, one case with mesenteric lymphadenitis, and one without any visible pathological lesions, where the $Y$. enterocolitica agglutinin titres were followed for several months from the acute onset of the symptoms.

\section{Patients with Chronic Regional Ileitis (Crohn's Disease)}

In this group, comprising 22 patients, the clinical diagnosis was chronic or subchronic regional ileitis. In most of them the diagnosis was histologically or radiologically confirmed. The symptoms had in all cases persisted for more than six months. The serological results are given in Table II. None of the patients showed agglutinin titres against $Y$. enterocolitica $\mathrm{O}$ antigen higher than $1 / 20$, nor were there any significantly raised agglutinin titres against $Y$. pseudotuberculosis type I.

TABLB II.-Incidence of Y. enterocolitica Agglutinins and Y. pseudotuberculosis Type I Agglutinins in Patients with Symptoms of Chronic Regional Ileitis (Crohn's Disease) or Diarrhoea of Varying Origin

\begin{tabular}{|c|c|c|c|c|c|c|c|c|}
\hline \multirow[t]{2}{*}{ Diagnosis } & & \multirow[t]{2}{*}{ Total } & \multicolumn{5}{|c|}{$\begin{array}{c}\text { Distribution of } \\
\text { Y. enterocolitica Agglutinins } \\
\text { (Masimal Titre) }\end{array}$} & \multirow{2}{*}{$\begin{array}{l}\text { Y. pseudo- } \\
\text { tuberculosis } \\
\text { Type I } \\
\text { Agglutinins } \\
=1 / 40\end{array}$} \\
\hline & & & $\leqslant 1 / 10$ & $1 / 20$ & $1 / 40$ & $1 / 80$ & $\geqslant 1 / 160$ & \\
\hline $\begin{array}{l}\text { Yrohn's disease } \\
\text { jiarrhoea ... }\end{array}$ & : & $\begin{array}{r}22 \\
148\end{array}$ & $\begin{array}{r}19 \\
140\end{array}$ & 3 & $=$ & $\overline{3}$ & $\overline{5}$ & $\overline{-}$ \\
\hline
\end{tabular}

- Positive culture of Y. enterocolitica from one patient.

\section{Patients with Diarrhoea of Varying Origin}

The 148 patients with diarrhoea as a main symptom were included in the study. Salmonella infection was known to exist in 14, and in 14 the diagnosis was ulcerative colitis. Only eight patients within this group showed $Y$. enterocolitica agglutinin titres above 1/40 (Table II) ; five of them, however, had rather high titres. In one case, where $Y$. enterocolitica was cultured from the stools, the maximal titre registered during the course of illness was $1 / 20,480$ (Fig. 3). Two of the patients, serologically positive regarding $Y$. enterocolitica, also had had abdominal pain suggesting acute appendicitis. Operation had, however, not been performed. The agglutinin curves in one of these cases is illustrated in Fig. 3. Agglutinins against $Y$. pseudotuberculosis were not found in any case.
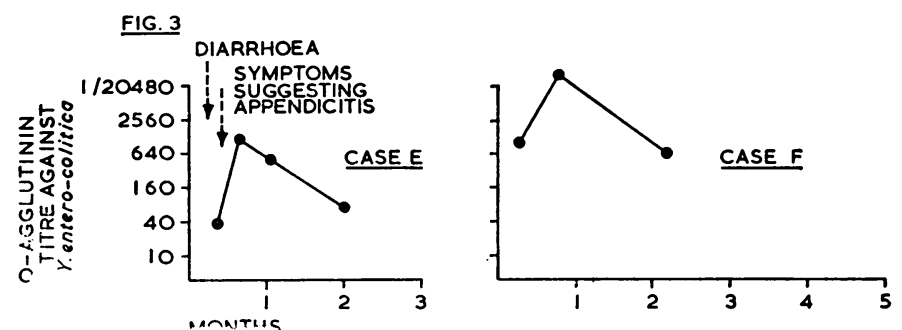

FIG. 3.-Y. enterocolitica $O$ agglutinin titre curves in two patients with diarrhoea and abdominal pain as initial symptoms. Case E: Symptoms of acute appendicitis. No operation. Case F: Diarrhoea, abdominal pains. Positive Y. enterocolitica culture.

\section{Control Groups}

The 1,351 in-patients with varying non-surgical diagnoses and the 431 blood donors served as controls. The serological results are shown in Table III. Among the in-patients $2.6 \%$ had $Y$. enterocolitica agglutinin titres $\geqslant 1 / 40$. Of 11 patients with titres of at least $1 / 160$ three had recently had diarrhoea and one had had transient abdominal pain, while abdominal symptoms in the remaining seven, so far as is known, had been lacking.

The incidence of $Y$. enterocolitica agglutinins in the blooddonor sera was the same as in the in-patient group-that is, $2.6 \%$ with a titre $\geqslant 1 / 40$. Only one blood donor showed a titre of $1 / 160$. Shortly before his visit to the blood bank this donor had had abdominal pain and diarrhoea.

TABLE III.-Incidence of Y. enterocolitica Agglutinins in Blood Donors and Unselected In-patients of the Departments of Internal Medicine and Infectious Diseases

\begin{tabular}{c|c|c|c|c|c}
\hline $\begin{array}{c}\text { Group } \\
\text { of } \\
\begin{array}{c}\text { Serum } \\
\text { Samples }\end{array}\end{array}$ & Total & \multicolumn{4}{|c}{$\begin{array}{c}\text { Distribution of Y. enterocolitica } \\
\text { Agglutinins (Maximal Titre) }\end{array}$} \\
\hline $\begin{array}{l}\text { Blood donors } \\
\text { In-patients }\end{array}$ & 1,351 & $\leqslant 1 / 10$ & $1 / 20$ & $1 / 40-1 / 80$ & $\geqslant 1 / 160$ \\
\hline
\end{tabular}

\section{Culture of $\mathbf{Y}$. enterocolitica}

Culture has been carried out in only a small number of the cases presented in this study. Nevertheless, $Y$. enterocolitica has been isolated from several patients. Apart from the case published by Carlsson et al. (1964), two further cases of bacteriologically verified human infection with $Y$. enterocolitica have recently been reported from this department by Winblad et al. (1966). The diagnosis in all three cases was acute terminal ileitis.

In the present study cultures have been done mainly in the group of patients subjected to appendicectomy. Culture material has been taken from the appendices, and in several cases also from the stools. In addition to the three cases already published isolations of $Y$. enterocolitica have been made from six patients presenting symptoms suggesting acute appendicitis, and also in one case with diarrhoea as a main symptom. All patients with a positive $Y$. enterocolitica culture also showed a positive $Y$. enterocolitica serology, of ten with the development of rather high agglutinin titres (Tables I and II).

\section{Histopathology}

In 23 patients subjected to appendicectomy the appendices were examined microscopically. Extirpated mesenteric lymph nodes from a few patients were also sent for histopathological examination. In nine cases, seven of which were positive to $Y$. enterocolitica serologically, small collections of leucocytes were seen in the germinal centres of the lymphoid tissue. This type of lesion may be described as a micro-abscess, until now not referred to any specific micro-organism (Special Plate, Fig. 4). No changes as in Masshoff's disease were found (Masshoff, 1953).

\section{Discussion}

In view of the fact that human infections with $Y$. enterocolitica were until recently almost unheard of, surprisingly large numbers of patients with antibodies against this bacterium have been found during the present study. $Y$. enterocolitica agglutinins were much more common in patients with symptoms suggesting acute appendicitis than in any other group investigated. The four cases of human mesenteric lymphadenitis with agglutinins against $Y$. enterocolitica described by Mollaret and Destombes (1964) belong to the same category.

A comparative presentation of the incidence of $Y$. enterocolitica agglutinins in the various groups is given in Table IV. The highest frequency of positive $Y$. enterocolitica serology was found in patients with acute terminal ileitis and mesenteric 
lymphadenitis. Several positive cases were also found in the group in which no pathological lesions were detected at operation and in patients with the diagnosis of acute appendicitis. However, it is not possible to separate the above-mentioned

TABLB IV.-Incidence of Y. enterocolitica Agglutinins in Sera from Different Groups of Patients and Normal Persons

\begin{tabular}{|c|c|c|}
\hline $\begin{array}{l}\text { Source of } \\
\text { Sera }\end{array}$ & Total & $\begin{array}{l}\text { No. of Cases with } \\
\text { Agglutinins } \geqslant 1 / 40\end{array}$ \\
\hline $\begin{array}{l}\text { Patients subjected to appendicectomy with acute } \\
\text { terminal ileitis or mesenteric lymphadenitis. }\end{array}$ & 33 & 23 \\
\hline $\begin{array}{l}\text { Patients subjected to appendicectomy without } \\
\text { macroscopical lesions } \ldots\end{array}$ & 17 & 3 \\
\hline Patients subjected to appendicectomy with & 45 & 7 \\
\hline $\begin{array}{l}\text { appendicitis } \\
\text { Supposed Crohn's disease or diarrhoea of varying }\end{array}$ & 45 & 7 \\
\hline $\begin{array}{l}\text { origin } \\
\text { Unselected in-patients and blood donors } \quad \ldots\end{array}$ & $\begin{array}{r}170 \\
1782\end{array}$ & $\begin{array}{r}8(4 \cdot 7 \%) \\
46(2.6 \%)\end{array}$ \\
\hline
\end{tabular}

categories of acute abdominal diseases into distinctive nosological entities on the basis of the clinical, serological, bacteriological, and histopathological data available.

Patients with a subchronic or chronic regional ileitis-that is, with the clinical diagnosis of Crohn's disease-were of special interest because of a possible relation between acute and chronic affection of the terminal ileum. These patients did not show high agglutinin titres against $Y$. enterocolitica in any cases. They were, however, investigated after at least six months of disease. Three patients out of 20 had low Y. enterocolitica agglutinin titres, which might indicate an earlier acute infection with or without connexion with the chronic enteric disease.

In the diarrhoea group the frequency of positive $Y$. enterocolitica serology did not much exceed that of the control groups of blood donors and patients with non-surgical diagnoses. The incidence of high $Y$. enterocolitica agglutinin titres in normal persons was found to be about $2.6 \%$. The low incidence of $\boldsymbol{Y}$. enterocolitica antibodies in these groups argues against $Y$. enterocolitica being an enteric commensal, stimulating antibody formation in cases of non-specific damage to the intestinal wall. Instead, it is reasonable to assume $Y$. enterocolitica to be actively pathogenic in those cases where antibodies against it are formed.

Cross-absorption studies with various strains of Escherichia coli, Proteus species, Salmonella species, and Gram-positive cocci have so far not revealed any high degree of cross-reaction between these bacteria and $Y$. enterocolitica. The absence of cross-reactions between $Y$. enterocolitica and $Y$. pseudotuberculosis has been noted by several authors (Knapp and Thal, 1963 ; Mollaret and Chevalier, 1S 4 ; Frederiksen, 1964).

Agglutinins against $Y$. enterocolitica were found much more often than agglitinins against $Y$. pseudotuberculosis type $I$ in all groups investigated. Only three out of 95 appendectomized fatients, and none in the other patient groups, showed $Y$. pseudotuberculosis agglutinin titres $\geqslant 1 / 40$.

Knapp and Masshoff (1954) observed that in the case of $Y$. pseudotuberculosis infection in Masshoff's disease high acrglutinin titres were already present at the time of operation. In the case of $Y$. enterocolitica infection the results of the present study indicate that usually no agglutinins are detectable at the time of onset of symptoms, while rather high titres can be demonstrated about a week later.

In some serologically positive cases histopathological examination revealed micro-abscesses inside the germinal centres of the lymphoid tissue. The significance of these findings for $Y$. enterocolitica infections will be the subject of further studies. in none of the examined cases could changes as in Masshoff's disease be detected.
Thus the high incidence of $Y$. enterocolitica agglutinins in certain groups of acute abdominal disease compared with the low incidence in normal persons and in other diseases, the rising antibody titre, and the positive $Y$. enterocolitica culture in several cases, strongly suggest that this micro-organism is an aetiological factor in human acute enteric infections with symptoms indicative of appendicitis.

\section{Summary}

Various groups of patients and blood donors were examined for agglutinins against Yersinia enterocolitica $O$ antigen and against $Y$. pseudotuberculosis type $\mathrm{I} \mathrm{OH}$ antigen. $Y$. enterocolitica agglutinins were found to be most common in patients with symptoms suggesting acute appendicitis, especially in those with acute terminal ileitis and mesenteric lymphadenitis, where agglutinin titres $\geqslant 1 / 40$ were found in 23 out of 33 patients. Rising antibody titres were demonstrated after the acute onset of the symptoms.

The incidence of $Y$. enterocolitica agglutinins in patients with diarrhoea of variable origin was $5.4 \%$. Patients with the diagnosis of Crohn's disease and those with non-surgical diagnoses did not significantly differ from healthy blood donors, where the incidence was $2.6 \%$.

The incidence of $Y$. pseudotuberculosis agglutinins was low in all groups investigated.

In several serologically positive cases $Y$. enterocolitica was isolated by culture from appendices or from the stools.

The results of this study support the view that $Y$. enterocolitica is a fairly common human pathogen, especially in acute diseases of the ileocaecal region.

\section{BIBLIOGRAPHY}

Akkermans, J. P. W. M., and Terpstra, J. I. (1963). T. Diergeneesk.,

Becht, H. (1962). Dtsch. tierärtztl. Wschr., 69, 626. Carlsson, M. G., Ryd, H., and Sternby, N. H. (1964). Acta path. micro-
biol. Scand., 62, 128 .

Crohn, B. B., and Yarnis, H. (1958). Regional Ileitis, 2nd ed. Grune \& Stratton, New York

Daniéls, J. J. H. M. (1963). Zibl. Vet.-Med., 10, 413.

— and Goudzwaard, C. (1963). T. Diergeneesk., 88, 96.

Dickinson, A. B., and Mocquot, G. (1961). f. app. Bact., 24, 252.

Frederiksen, W. (1964). Proc. XIV Scand. Congr. Path. Microbiol., Oslo, p. 103.

Hannoun, C., Mollaret, H. H., and Thiaucourt, P. (1961). Presse méd., 69, 971.

Hässig, A., Karrer, J., and Pusterla, F. (1949). Schweiz. med. Wschr., 79, Kiaer, W. (1960). Ugeskr. Lag., 122, 561.

Kjellén, L., Sterner, G., and Svedmyr, A. (1957). Acta paediat.
(Uppsala), 46, 164.

Knapp, W. (1963). Arch. Hyg. (Berl.), 147, 369.

— and Masshoff, W. (1954). Disch. med. Wschr., 79, 1266.

- and Steuer, W. (1956). Z. Immun.-Forsch., 113, 370.

- and Thal, E. (1963). Zbl. Bakt., I. Abt. Orig., 190, 472.

Masshoff, W. (1953). Disch. med. Wschr., 78, 532.

Mollaret, H. H. (1960). Presse méd., 68, 1375.

-(1962). Le Bacille de Malassez et Vignal. Paris.

- and Chevalier, A. (1964). Ann. Inst. Pasteur, 107, 121. and Destombes, P. (1964). Presse méd., 72, 2913.

- and Lucas, A. (1965). Ann. Inst. Pasteur, 108, 121.

Schleifstein, J. I., and Coleman, M. B. (1939). N.Y. St. F. Med., 39, 1749.

Winblad, S., Nilchn, B., and Jonsson, M. (1966). Acta path. microbiol. Scand. In press. 


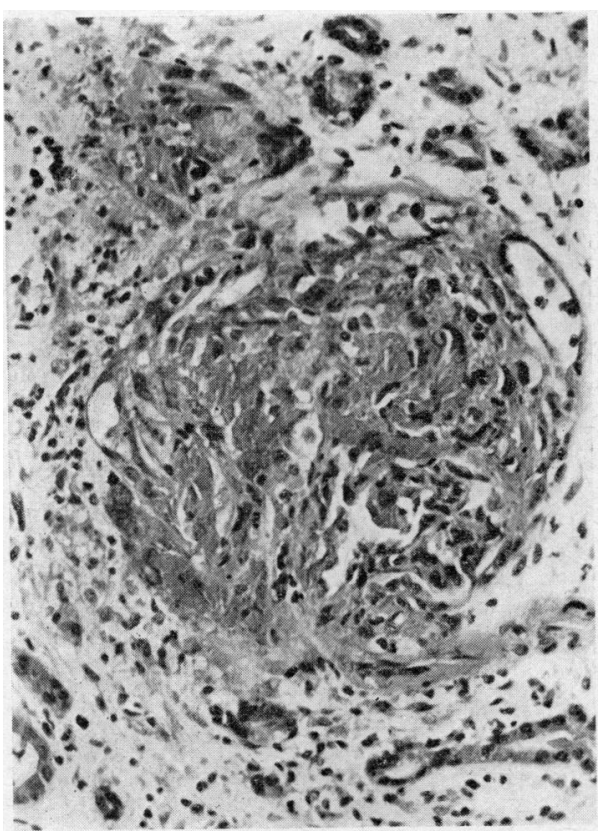

FIG. 1.-Case 2. Necrotizing glomerulonephritis. (H. and E. $\times 260$.)
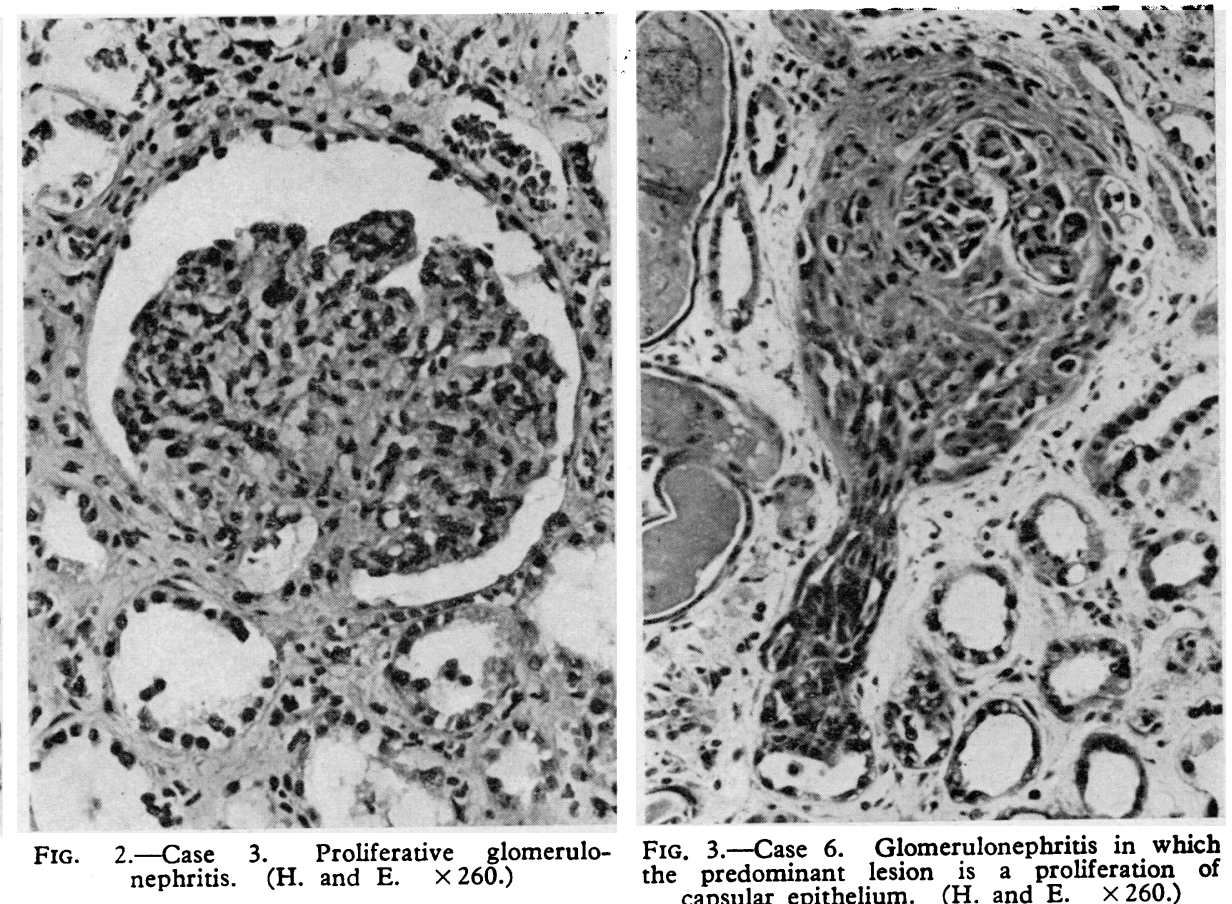

FIG. 3-Case 6. Glomerulonephritis in which the predominant lesion is a proliferation of capsular epithelium. (H. and E. $\times 260$.)

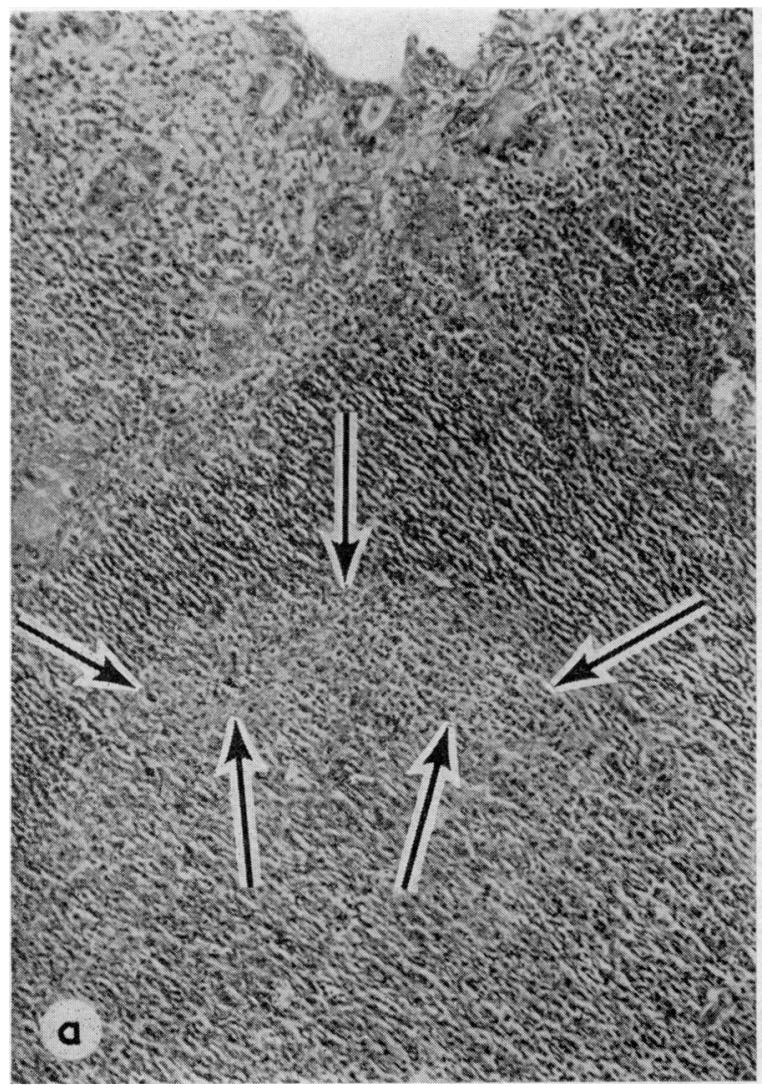

Fig 4--Sections from the wall of the appendix in two cases of $Y$. enterocolitica infection. In the germinal centre small collections of leucocytes (microabscesses) are seen. Haematoxylin-eosin staining. (a) $\times 120$. (b) $\times 192$.

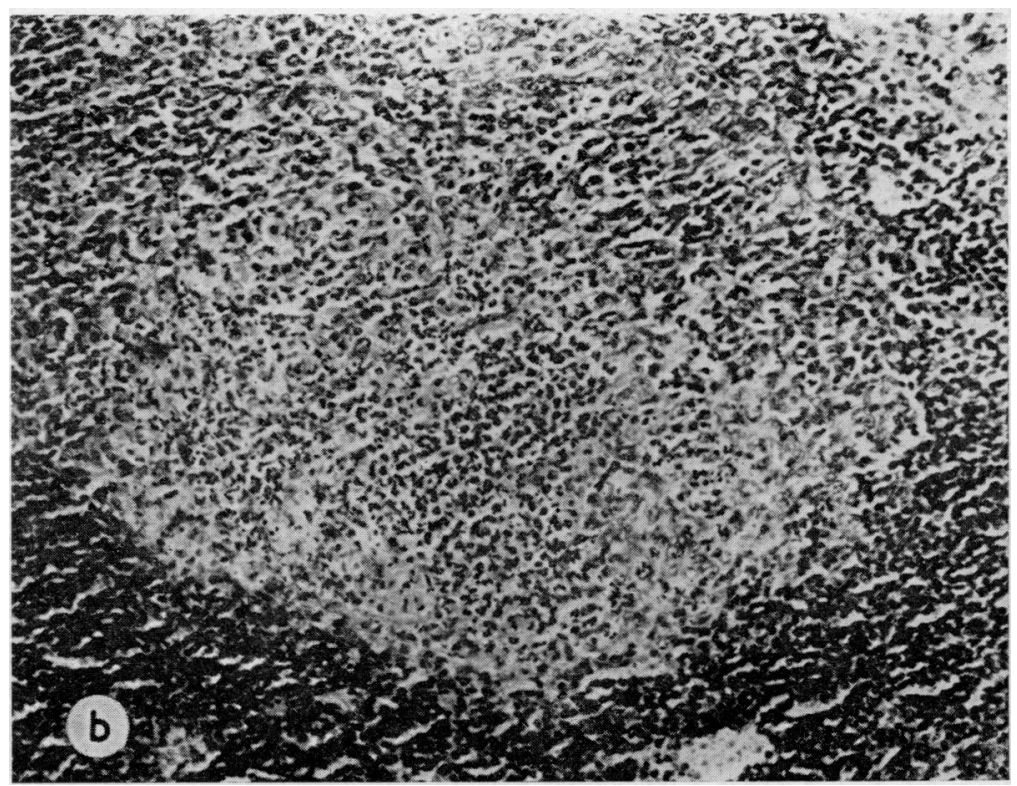

